How to cite this article:

Rahim, N., \& Jamaludin, Z. (2019). Write-rite: Enhancing handwriting proficiency of children with dysgraphia. Journal of Information and Communication Technology, 18(3), 253-271.

\title{
WRITE-RITE: ENHANCING HANDWRITING PROFICIENCY OF CHILDREN WITH DYSGRAPHIA
}

\author{
Norsafinar Rahim \& Zulikha Jamaludin \\ School of Computing, Universiti Utara Malaysia, Malaysia, \\ norsafinar@yahoo.com; zulie@uum.edu.my
}

\begin{abstract}
Many children have limitations that significantly impact their writing ability, such as physical, cognitive, and motor limitations, all of which need to be overcome for a good level of written expression. This study addresses problems and difficulties in mastering the process of writing among dysgraphic children. The most suitable method to overcome these problems is to provide activities and exercises that can help children with dysgraphia improve visual-motor integration that is correlated with writing skills. With this aim in mind, a dysgraphic-customised application called Write-Rite has been designed to support children with dysgraphia, through activities and exercises, in order to fulfil their unique needs. This study is an attempt in designing and evaluating the Write-Rite application that provides a stimulating and interactive experience for dysgraphic children to practise writing at different levels of difficulty to facilitate the learning process. This study was conducted in two primary schools in Kedah, with five participants (aged seven to 12) who were observed and evaluated for five weeks. Data was compiled through observations, recorded handwriting performances and a selfgenerated rubric to track the following: formation of letters, slant, size and proportion, alignment, spacing and line quality. The results of a preliminary evaluation and assessment of "Write-Rite" found that this application fulfilled its role in terms of optimising writing proficiency among children with dysgraphia.
\end{abstract}


Keywords: Dysgraphia, dysgraphic-customized application, handwriting, intervention and learning disability.

\section{INTRODUCTION}

Dysgraphia is a type of specific learning disability that affects handwriting and makes the act of writing difficult. Individuals with dysgraphia have difficulty expressing thoughts in written form, especially related to their ability to recall patterns of alphabets or symbols (Prunty \& Barnet, 2017; Keller, 2001; Miceli \& Capasso, 2006; Raza, Arif, Darvagheh, \& Hajjdiab, 2017). Children suffering from dysgraphia avoid writing tasks, which is associated with the absence of motor skills and cognitive impairment. Dysgraphia is not always isolated, and it often occurs with other disabilities, such as dyslexia, dyscalculia, attention deficit hyperactivity disorder (ADHD), dyspraxia, developmental coordination disorder, dysorthographia, visual-spatial perceptual disorder, academic anxiety syndrome, and autism spectrum disorder (Mather, 2012; Chia \& Ong, 2009; Cortielle \& Horowitz, 2014). Depending on the definition and variables studied, between $30 \%$ and $47 \%$ of students face problems with spelling and writing at the same time (Barisic, Kohnen, \& Nickles, 2017).

The most frequent problem with dysgraphic children is in the quality of their handwriting. Handwriting difficulties, unfortunately, may have serious consequences on students' academic achievement (Kushki, Schwellnus, Ilyas, \& Chau, 2011; Van Drempt, McCluskey, \& Lannin, 2011). Hence, it is important to identify handwriting difficulties among dysgraphic children as early as possible for the success of any supportive intervention. When planning for students with learning difficulties, the first consideration is to support learning differences from the beginning. Technology can also be integrated into education programmes and practices to facilitate learning for students of all abilities (O'Bannon, Puckett, \& Rakes, 2006; Connell, Freed, \& Rothberg, 2010). The benefits of employing technology include the development of interactive experiences that can help motivate students by assisting them in addressing their learning difficulties. Technology provides new source for researchers and educators the importance of children's active use of technology in decision-making, illustrating ideas and also technology resources in writing and drawing (Couse \& Chen, 2010; NAEYC, 2012; NCATE, 2008).

Technology can be used to accommodate instructions to help both children who do and do not struggle with writing (Berninger, Nagy, Tanimoto, Thompson, \& Abbott, 2015; Bryant et al., 2015; Bryant, Seok, Ok \& Bryant, 
2012; Niedo, Tanimoto, Thompson, Abbott \& Berninger, 2016). It is always important to find the best match between technology and the learner. Children can concentrate better when engaging in activities related to computer-based learning systems available in different modes and technologies that encompass static websites to dynamic tutoring systems (Wang, Ryu, \& Katuk, 2015). Peterson-Karlan and Parette (2007) reviewed technologies that can support struggling writers including word processing, spell checkers, word prediction, speech recognition and word cuing. Although these solutions can provide some motivation for children as alternatives to handwriting, they do not improve the children's abilities and skills in the handwriting process. The best practice for the use of technology tools is that it should be linked to the problem it is addressing. Therefore, the best approach is by attempting to help dysgraphic children refine their motor ability and skills with exercises/activities aimed at improving their visual spatial coordination, thus acquiring their writing skills. To this extent, using application technology is the alternative to assist teachers and dysgraphic children as it provides an interesting approach to writing using stylus or touch surface using fingers. In this paper, an application tool is proposed to help children with dysgraphia by providing them with learning activities at different levels of difficulty to improve their writing skills. This application creates a unique learning experience and facilitates enhancement of learning techniques, besides increasing children's motivation, fostering self-competition, and boosting their confidence and self-esteem (Berninger et al., 2015; Rello \& Baeza-Yates, 2013). In the meantime, the use of tablets is rising in popularity amongst students, which could be harnessed to enhance interactivity and overall engagement.

\section{SYSTEM FUNCTIONALITY}

This paper presents a dysgraphic-customized application tool called WriteRite that allows dysgraphic children to practice writing tasks using tablets. Write-Rite allows children with dysgraphia to practise writing tasks at different levels of difficulty. These activities consist of three levels (1) Level 1: connecting dots in texts, (2) Level 2: connecting points in words, and (3) Level 3: self-written words. The activities were adapted from Giordano and Maiorana (2014) where a system is proposed to assist dysgraphic children by prompting them to trace letters, therefore improving their writing ability.

The Write-Rite application was developed based on the understanding of the nature of dysgraphia and how it affects learning. The system stores data characterizing writing rules and allows teachers to choose texts based on students' abilities. Each writing result is compared to a reference database 
containing a set of correct rules, prepared by experts. Teachers can select any texts for each level of difficulty and the data will be stored in the database. Based on the final writing results, dysgraphic students and teachers will get their score after the result is compared with the reference rules stored in the database. This application differs from other existing applications. One of the advantages of this application is that there is a scoring system based on the percentage of how many words a student can trace in a given task. Figure 1 illustrates the context diagram for Write-Rite.

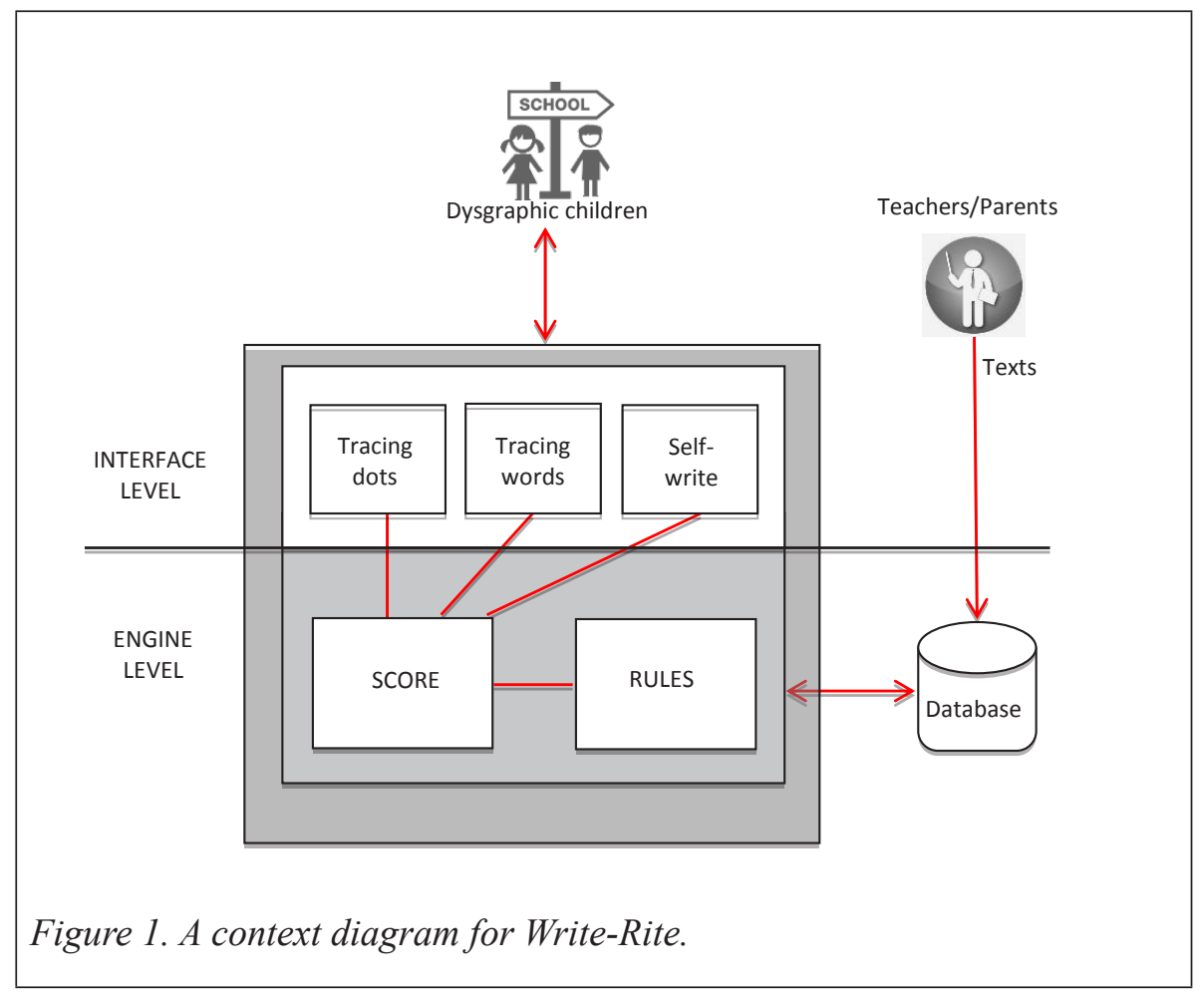

\section{Design Principles}

The design of the Write-Rite application addresses problems inherent in dysgraphic children based on the following principles (Prunty \& Barnett, 2017) in that the application:

1. Allows the teacher to monitor progress in students' handwriting performance.

2. Stores the entire writing process in order to analyze the writing progress of individual students. 
3. Offers immediate visual feedback to students to focus on their improvement.

4. Enables the teacher to personalize writing activities based on the needs of each student.

5. Provides a simple interface, usable for children with dysgraphia who require rehabilitation exercises in order to improve their handwriting skills.

Based on Figure 1, there are three types of users: administrators, teachers, and students (children with dysgraphia). Before the students can access the application, a teacher or an administrator will determine the selection of exercises and set the individual learning paths of the students. Students need to follow instructions and complete each task in order to proceed to the next level of activity. The system stores immediate feedback including statistical marks of the students for each activity. An example of teacher interface is shown in Figure 2.
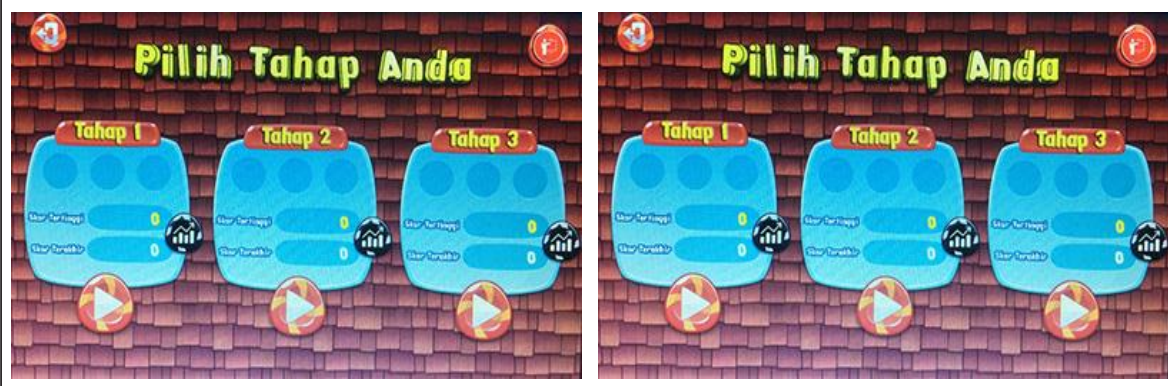

Figure 2. Write-Rite interface for teachers.

Here, the application allows the teacher to first select the level of difficulty from three options; 1) Level 1: connecting dots in texts, 2) Level 2: connecting points in words, and c) Level 3: self-write. The teacher can select any letter based on each student's needs and all tracing logs for each student are stored separately in a database as reference of the students' individual performance. For example, if a student is having problems with the letter E, then he/she can do the same task repeatedly. The student interface, shown in Figure 3, is developed to allow students to make their own tracings according to the type of exercise assigned by the teacher.

Based on Figure 3, students can start tracing letters by referring to the numbered arrow displayed. Marks will be deducted if students trace the letters 

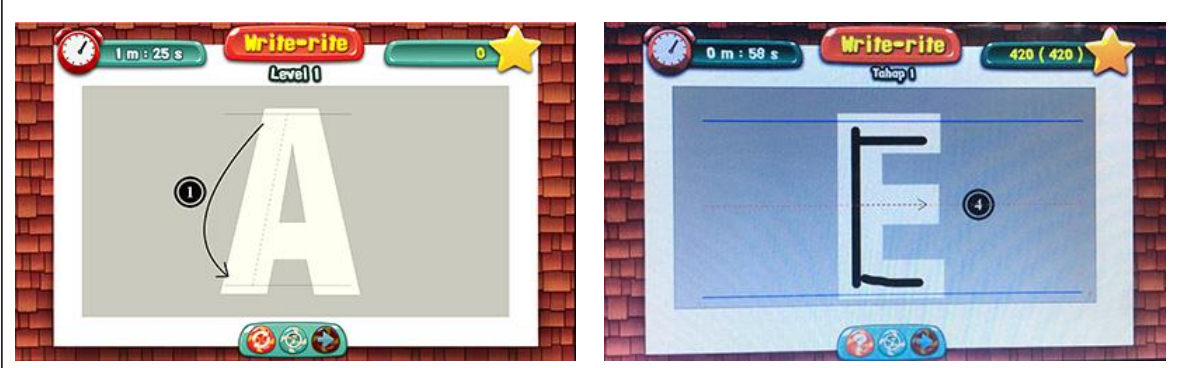

Figure 3. Write-Rite interface for students.

outside of the given area; higher marks indicate better accuracy in the letters traced. There are three buttons at the lower part of the interface, which allow students to obtain feedback on a completed exercise, to go to the next exercise, or to exit a page. Students can only view the interface specified by their teachers. This application allows personalized exercises on the basis of collected statistics. This information is useful in pinpointing each student's difficulties and customizing their learning paths. The teacher can obtain a report per student during the tracing process at different levels, as shown in Figure 4.

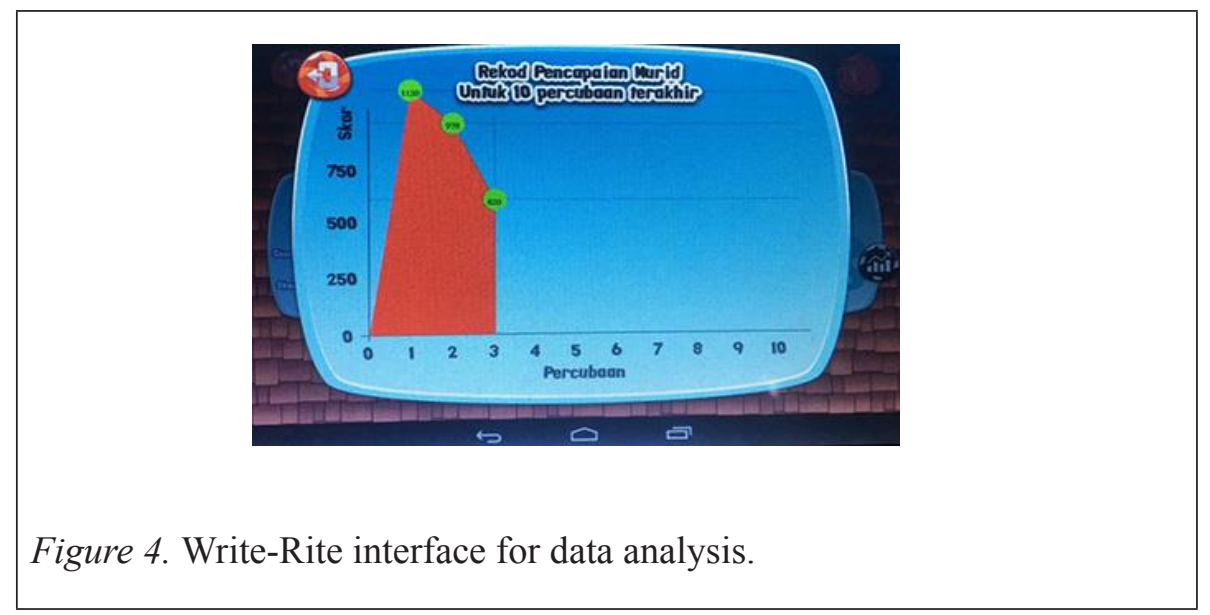

\section{METHODOLOGY}

This research used a quantitative evaluation approach by observing dysgraphic children's handwriting in order to appraise the effectiveness of the application. Data on handwriting samples from dysgraphic children were collected 
throughout the stratified sampling technique. Stratified sampling technique was used in this research as the samples involved were known, (Scheaffer, Mendenhall III, \& Ott, 2006).

\section{Participants}

Five dysgraphic children participated in this experiment in two successive evaluation sessions. This number of children confirmed the number of test users required in an ordinary usability test. In an iterative development process, the literature proposed five to 10 users per test round (Kaikkonen, Kekäläinen, Cankar, Kallio, \& Kankainen, 2005; Tullis \& Albert, 2013). These children underwent a formal diagnosis of learning disabilities from outreach programmes conducted by the Kedah State Education Department before obtaining verification from the psychiatrist. This study was conducted in two primary schools involving researchers, teachers and the dysgraphic children as the participants. These children, who were categorized as dysgraphic may also have other learning disabilities such as dyslexia, Attention Deficit Hyperactive Disorder (ADHD), or dyscalculia. These children had average academic performances and were assigned to special classes in their respective schools in Kedah. These children, aged seven to 12 were involved in the evaluation process. The average time for users to complete a level of activity was measured from a minimum of one minute to a maximum of two minutes.

\section{Assessments}

All the participants were tested individually. Each participated in the experiment under similar environmental conditions i.e. in a quiet classroom in their respective schools. The participants performed handwriting tasks by writing upper case and lower case letters repeatedly through recall on lined papers. The participants completed an alphabet task and it was selected to assist in identifying each error or weakness of the individual letters required for handwriting. Performance on this task was recorded and observed at three stages of the process: pre-intervention, during intervention and postintervention. Every movement, starting from the participants' pen holding manner, being in a ready position to write, and starting to write, were recorded in order to analyze for improvements. Based on the video taken, the alphabet task was initially played and replayed in slow motion in order to observe handwriting production. The movement of the alphabet task was administered to determine the general motor coordination abilities in the participants. The video was paused if there was a need to allow for accurate observation of the writing process. From the above assessment, a range of measures were 
obtained to align with handwriting legibility characteristics as the participants showed significant progress in their handwriting skills with scores based on a self-generated rubric as shown in Table 1. The participants' performance on these two tasks at the: beginning of the research (week 1) and end of the research (week 5) was analyzed in various ways to compare whether the Write-Rite application correlated with an improvement in the participants' handwriting. As a whole, the activities conducted can be summarized in a diagram in Figure 5.

Short session

-10-15 mins letter identification activities in class.

\section{PRE-INTERVENTION}

Assess students individually using pencil and lined paper.

(Write the entire alphabets in lower case and upper case letters)

- Alphabet task

- Copying task

\section{DURING INTERVENTION}

Assess students individually using Write-rite application.

- Level 1: Model with dotted line

- Level 2: Model marked with numbered arrows

- Level 3: Self writing

\section{POST-INTERVENTION}

Assess students individually using pencil and lined paper.

(Write the entire alphabets in lower case and upper case letters)

- Alphabet task

- Copying task

Collect samples of students' written work during preintervention and post-intervention for analysis purposes.

Figure 5. Overall activities conducted for dysgraphic children. 


\section{ANALYSIS OF DATA}

\section{Pre-Intervention}

This research was intended to obtain a preliminary evaluation and assessment of the Write-Rite tablet application for children with dysgraphia. The participants were given tasks where they needed to write upper case and lower case letters repeatedly via recall on lined papers. The alphabet tasks was to measure orthographic and motor integration that required the participants to retrieve from memory and produce alphabet letters, integrating orthographic symbols and motor output. According to Graham, MaCarthur, and Fitzgerald (2007), teaching the alphabet in the order of A-B-C may not be the best approach. The participants were asked to write in their usual style. Sample writing outputs from the five participants, consisting of alphabet letter writing, were measured and examined for various key factors and to note if there was any improvement in writing skills. The writing process was recorded, and the writing samples were assessed according to all elements of legibility based on Mather, Wenddling, and Roberts (2009). The handwriting legibility characteristics consisted of six interrelated characteristics, namely letter formation, slant, size and proportion, alignment, spacing, and line quality. A self-generated rubric mark from 1 (weak) to 5 (outstanding) was used to determine the areas of strengths and weaknesses of each participant. The overall scoring or quality for each category was marked as 1 (weak), 2 (poor), 3 (satisfactory), 4 (good) and 5 (outstanding). In addition to this rubric, the sample handwriting output was also marked for each error and mistake made (Figure 6).

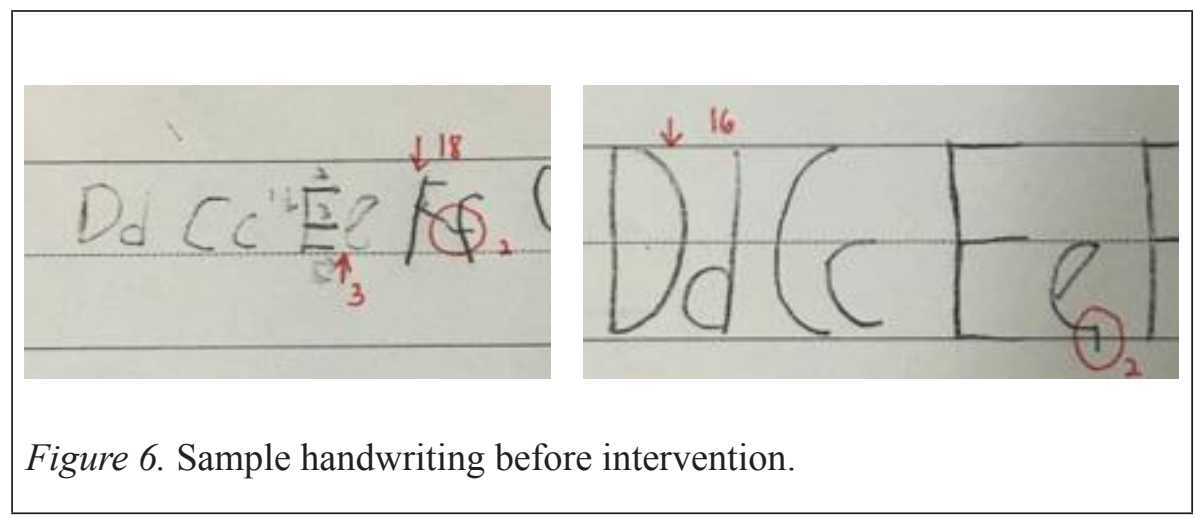




\section{During Intervention}

The participants were equipped with the Write-Rite application installed in their tablets with the assistance of their teachers to guide them in using the application. The teachers observed the participants while they were interacting with the application to elicit their performance. Each participant was allowed a period of three weeks to explore all features of the application. They had to perform all exercises given by their teachers within a certain period of time in order to proceed to the next level of activities. Figure 7 shows the flow of activities required by each participant to perform using the Write-rite application, starting from level 1.

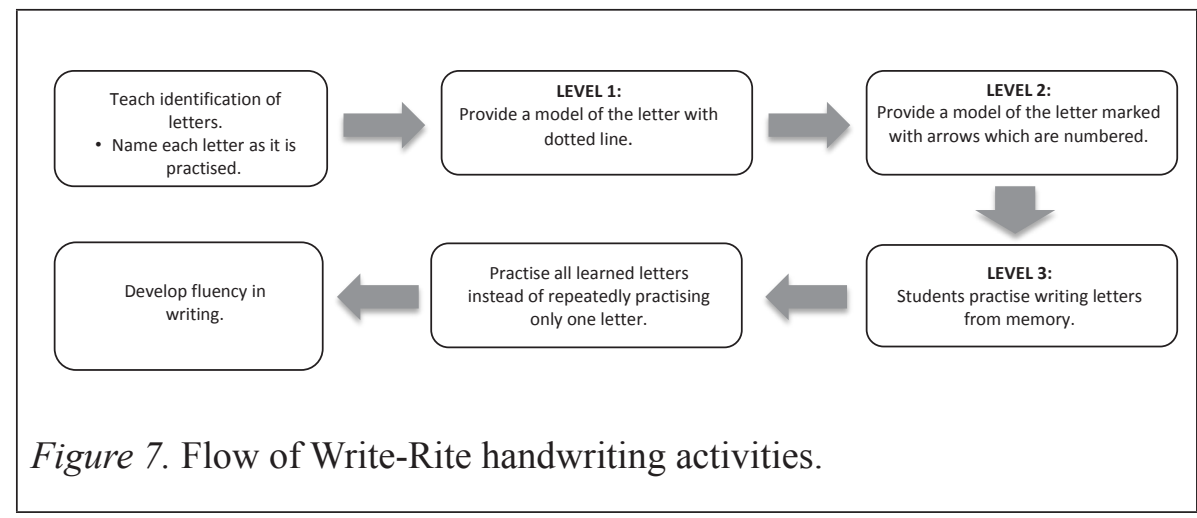

Write-Rite provides the model of a letter marked with numbered arrows to help students remember which way to move and this encourages the practice of using visual memory. Recalling letter formations is difficult for dysgraphic children because they need to follow rules in order to write in a correct way. Therefore, the Write-Rite application enables the dynamic use of fingers such that they can move in the correct direction required for the formation of letters. A recent study showed that, tracing and copying letters using finger formation on a tablet is ideal for students learning to form letters equally (Tanimoto, Thompson, Berninger, Nagy \& Abbott, 2015; Steele, Weber, McLaughlin, Donica, Derby, \& McKenzie, 2015; Zaki, Wook, \& Ahmad, 2017). The connection between tracing letters by finger and work of selection of the brain can improve the memory retrieval of students (Puranik \& Al Otaiba, 2012). It is only with extensive practice, can letter production and handwriting skills become legible; and students are then able to focus on other aspects of writing, such as spelling, spacing, and punctuation (Halsband \& Lange, 2006; Palmis, Danna, Velay, \& Longcamp, 2017). Figure 8 shows a dysgraphic child using the Write-Rite application during the learning process in the classroom. 


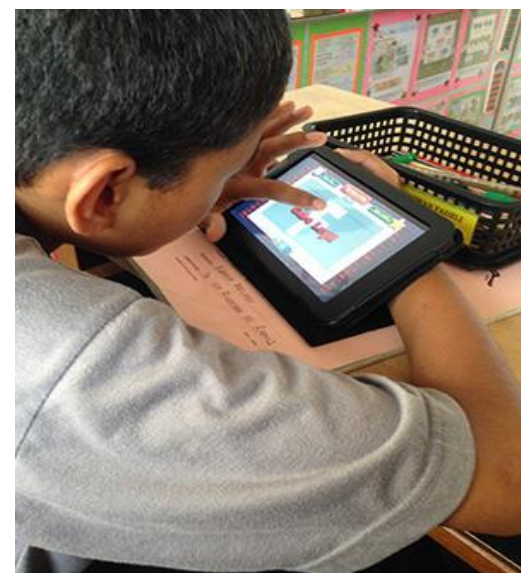

Figure 8. A dysgraphic child using the Write-Rite application.

\section{Post-Intervention}

After three weeks of using the application, the participants had to perform the same tasks given to them before the intervention to take note of any improvement in their writing skills. All environmental factors were kept as similar as possible to the writing conditions the children experienced before intervention. The movement of alphabet task was administered to determine general motor coordination abilities among the participants. Figure 9 shows the sample handwriting output that was marked for each error and mistake made after completing the exercises in the Write-Rite application.

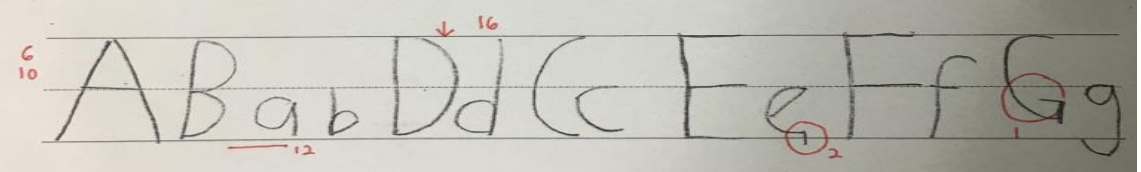

Figure 9. A handwriting sample after intervention.

\section{RESULTS}

The feedback data was computed using Excel spread sheet software for analysis purposes. Table 1 shows the analysis of the participants' handwriting 
for week one and week five. After five weeks of handwriting intervention, data on the writing samples of the participants from week one and week five were compared.

\section{Table 1}

\section{Results of handwriting problems}

\begin{tabular}{|c|c|c|c|c|c|}
\hline \multirow{2}{*}{ Beginning of research (Week 1) } & \multicolumn{5}{|c|}{ Student } \\
\hline & S1 & $\mathrm{S} 2$ & S3 & S4 & S5 \\
\hline $\begin{array}{l}\text { 1. Letter formation } \\
\text { - Is the handwriting legible? } \\
\text { - Are all letters formed correctly? } \\
\text { - Is any letter(s) reversed? }\end{array}$ & 1 & 1 & 2 & 1 & 1 \\
\hline $\begin{array}{l}\text { 2. Slant } \\
\text { - Is the slant appropriate? } \\
\text { - Is the slant consistent? }\end{array}$ & 2 & 2 & 3 & 2 & 2 \\
\hline $\begin{array}{l}\text { 3. Size and proportion } \\
\text { - Is the size of upper/lower case letters correct? } \\
\text { - Is the letter size consistent? }\end{array}$ & 1 & 1 & 2 & 2 & 1 \\
\hline $\begin{array}{l}\text { 4. Alignment } \\
\text { - Are the letters aligned correctly? } \\
\text { - Are the words aligned horizontally and vertically? }\end{array}$ & 1 & 2 & 3 & 2 & 1 \\
\hline $\begin{array}{l}\text { 5. Spacing } \\
\text { - Is the spacing between letters and words correct? } \\
\text { - Is the spacing between letters and words consistent? }\end{array}$ & 2 & 1 & 3 & 1 & 1 \\
\hline $\begin{array}{l}\text { 6. Line quality } \\
\text { - Is the line quality correct? } \\
\text { - Is the line quality consistent? }\end{array}$ & 2 & 2 & 2 & 2 & 2 \\
\hline
\end{tabular}

\begin{tabular}{l|c|c|c|c|c}
\hline \multirow{2}{*}{ End of research (Week 5) } & \multicolumn{5}{|c}{ Student } \\
\cline { 2 - 6 } & S1 & S2 & S3 & S4 & S5 \\
\hline $\begin{array}{l}\text { 1. Letter formation } \\
\text { - Is the handwriting legible? }\end{array}$ & & & & & \\
- Are all letters formed correctly? & 3 & 3 & 5 & 4 & 4 \\
- Is any letter(s) reversed? & & & & & \\
\hline
\end{tabular}




\begin{tabular}{|c|c|c|c|c|c|}
\hline \multirow{2}{*}{ End of research (Week 5) } & \multicolumn{5}{|c|}{ Student } \\
\hline & S1 & $\mathrm{S} 2$ & S3 & S4 & S5 \\
\hline $\begin{array}{l}\text { 2. Size and proportion } \\
\text { - Is the size of upper/lower case letters correct? } \\
\text { - Is the letter size consistent? }\end{array}$ & 3 & 4 & 5 & 4 & 3 \\
\hline $\begin{array}{l}\text { 3. Alignment } \\
\text { - Are the letters aligned correctly? } \\
\text { - Are the words aligned horizontally and vertically? }\end{array}$ & 3 & 4 & 4 & 4 & 4 \\
\hline $\begin{array}{l}\text { 4. Spacing } \\
\text { - Is the spacing between letters and words correct? } \\
\text { - Is the spacing between letters and words consistent? }\end{array}$ & 4 & 4 & 5 & 4 & 4 \\
\hline $\begin{array}{l}\text { 5. Line quality } \\
\text { - Is the line quality correct? } \\
\text { - Is the line quality consistent? }\end{array}$ & 3 & 4 & 4 & 4 & 4 \\
\hline
\end{tabular}

Based on Table 1, effective handwriting requires legibility, which refers to the clarity and accuracy of the letter forms. Before writing, participants must recall the representation of the letter and then they start to coordinate the motor patterns in order to form the letters. They must also take into consideration the spacing needed between the letters and words and the consistency in placing the letters on the writing lines. Legibility in handwriting involves six interrelated characteristics: (1) letter formation composition of the stroke; (2) slant, refers to the consistency in the direction of the writing; (3) size and proportion, the size of the letters and the proportional size between upper case and lower case letters; (4) alignment, or uniformity of size and consistency on the writing line; (5) spacing, the consistency and amount of spacing between letters and words; (6) line quality, the steadiness and thickness of the line (Mather, Wendling, \& Roberts, 2009). The handwriting samples were scored based on the six interrelated characteristics using a self-generated rubric to determine the errors and mistakes made by the participants. In general, the self-generated rubric measured: 1 (weak), 2 (poor), 3 (satisfactory), 4 (good) and 5 (outstanding).

Improvements in the participants' handwriting were observed over the course of this research. This research discovered that out of the five participants with dysgraphia, three were boys and two were girls, which meant that 
handwriting problems appeared to be more common among school-aged boys than girls. This was similar to the published findings in the literature where it was reported that approximately two-thirds of school-aged students who had been identified with learning disabilities were male (Mohamad, 2018). Figure 10 demonstrates the statistical analysis of handwriting difficulties among the participants in this study.

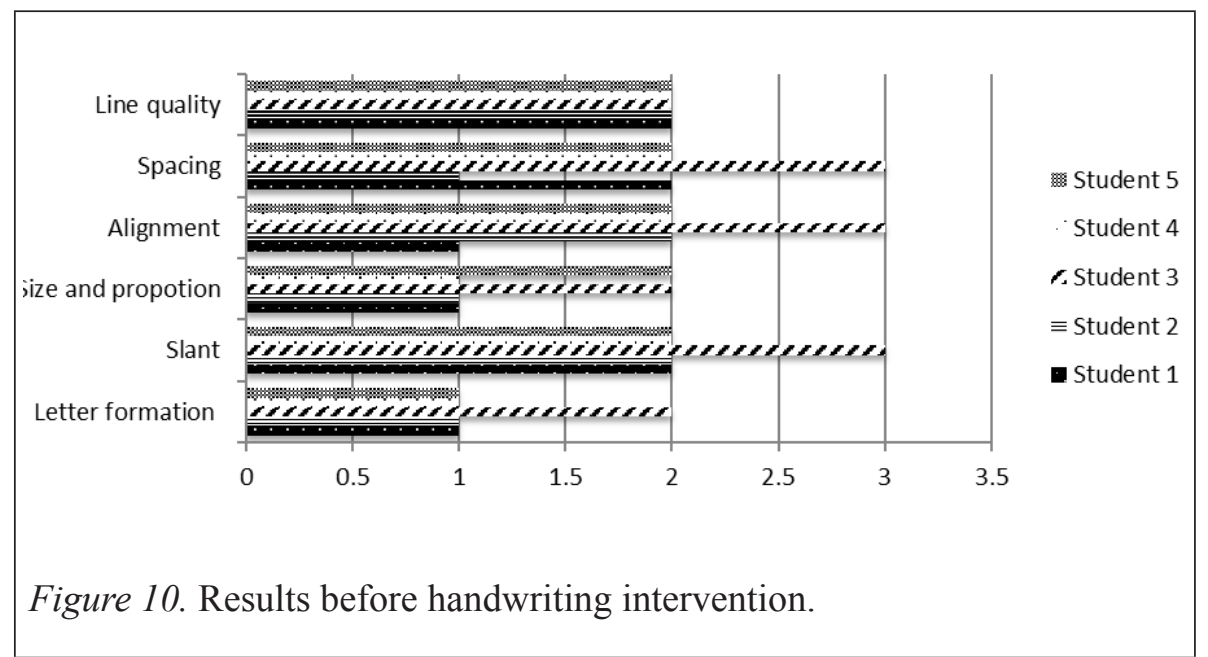

Based on Figure 10, $80 \%$ of the participants faced difficulties related to letter formation, size and proportion. They only achieved an average score of 1 and 2 for most handwriting characteristics measurement. Letter formation was found to be the most problematic for these participants. Only one participant scored a rubric mark of 2 (poor). Meanwhile, the rest had relatively similar problems such as line quality, spacing, alignment, and slant in performing their writing tasks.

In addition, direct instructional modelling with numbered arrow cues was utilized to provide a motoric model for the dysgraphic participants to imitate. The numbered arrows showed the direction of the strokes for each letter. It was intended to enable the participants to produce letters using the correct strokes. Figure 11 shows the improvements made with regard to using lines correctly, specifically when writing upper case letters. Before intervention, the upper case letters were formed only on the top row. After intervention, it was observed that the participants were able to write the letter, "E" with the letter remaining in between the bottom and middle lines. 

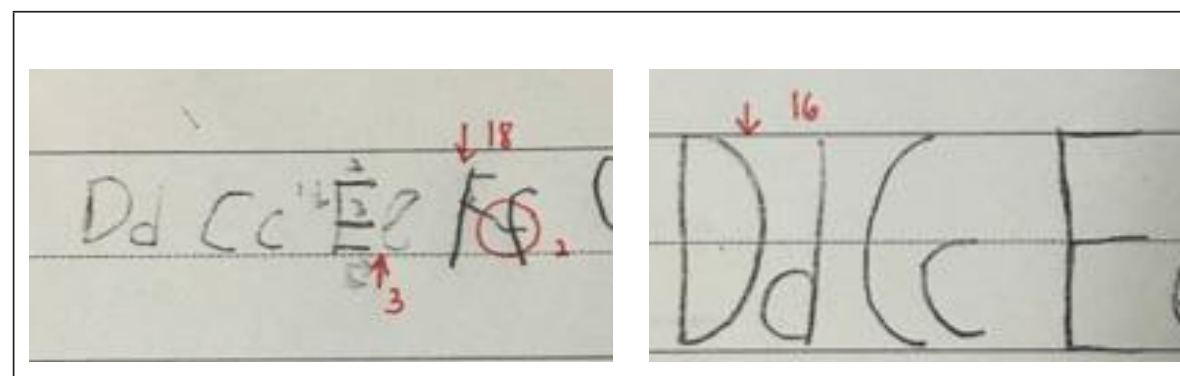

Figure 11. Improvement in writing using lines.

Data collection after intervention was taken at the end of week five. The participants were observed to have gained confidence in their handwriting. Based on Figure 12, the participants made progress for each handwriting characteristic measured after completing all the activities in the Write-Rite application.

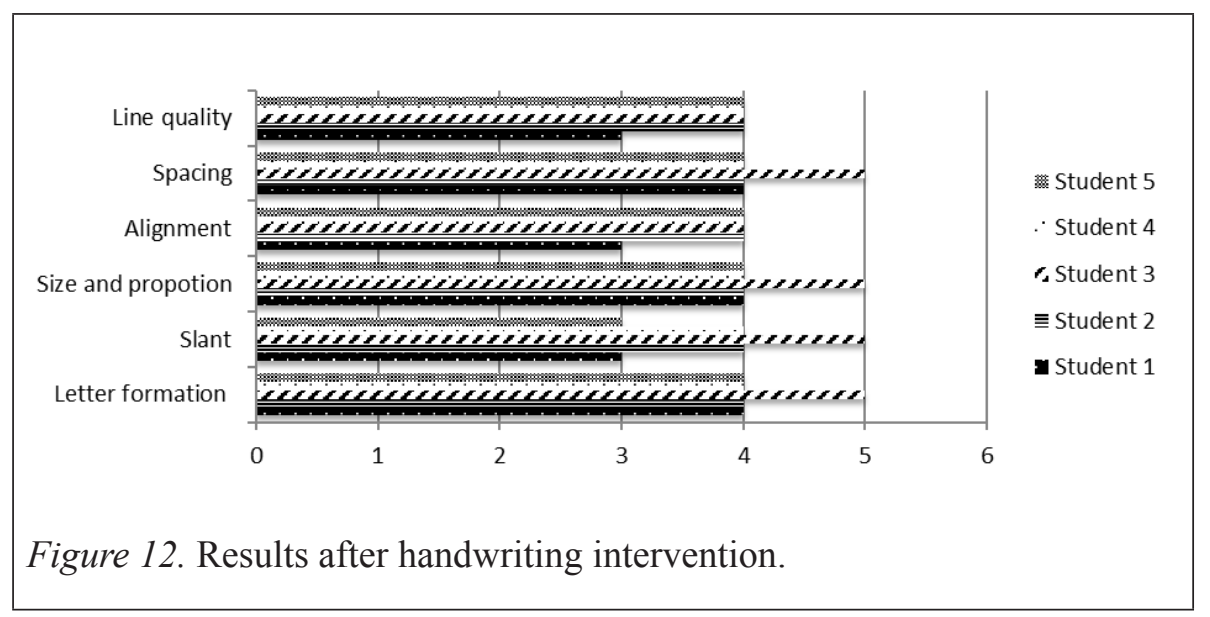

The participants showed significant progress in their handwriting skills at the end of the study, with scores from poor (2) to good (4), based on the rubric used. These results indicated that overall, the participants had improved dramatically in their handwriting skills from several aspects, that their letters: were formed correctly, written on a line, modelled using proper spacing and size, were consistently well-proportioned for both upper and lower case letters, and generally, their writing looked neat. Write-Rite application was designed as a fundamental strategy of imitation, tracing, and copying. Thus, the preliminary results of the application evaluation showed the effectiveness of the Write-Rite application in advancing handwriting skills for children with 
dysgraphia. Dysgraphic children are not able to develop their writing skills without having actual handwriting skills first.

\section{DISCUSSION}

The dysgraphic children in the study had grown comfortable exploring the Write-Rite application and had made significant progress in a short period of time. There were many factors that seemed to have impacted on the success of the handwriting development for the dysgraphic children. Prior to the start of the study, these dysgraphic children had problems with alignment as they did not use lines as a guide when forming letters. Letters needed to be initiated in their proper placement between lines and capitals had to be used correctly. In general, lower case letters are formed using the bottom and middle lines. Writing requires excellent motor skills. Some of the children had writing problems because they experienced stiffness in their hands which made it difficult for them when holding the pencil and moving their hands during writing. On the other hand, children who had problems with spacing and alignment simply copied letters and words without understanding the meaning of the written sentences. Thus they did not feel the need to space words.

The children's motivation to write was low at the beginning. Given that the intervention sessions using Write-Rite was designed with a number of short tasks or activities, it helped to maintain the children's attention span. At the same time, it committed them to all the activities and prevented them from becoming bored or frustrated. After three weeks of handwriting practice using the Write-Rite application, $80 \%$ of the children started writing specific letters correctly and their handwriting had become more fluid. By using the writing lines, the application played a pertinent role in assisting the children to differentiate between upper and lower case letters, which led to more legible handwriting. The children in the study made significant improvements in letter formation, size, proportion and alignment.

\section{CONCLUSION}

Write-Rite was designed with user requirement development involving dysgraphic children and teachers with hands-on experience to overcome handwriting difficulties, and to measure progress in the development of handwriting skills. The application conveyed a pleasant environment and produced exercises that helped dysgraphic children focus their attention on 
the screen. Moreover, the children were able to easily recognize and utilize all the features of the application independently. Findings of the present study showed that initially the children with dysgraphia appeared to perform less proficiently on measures of letter formation, size and proportion, and spacing. However, as a result of a comprehensive five-week handwriting evaluation, it can be concluded that the application has fulfilled its role in terms of the dysgraphic children's improved legibility, which encompassed six interrelated characteristics, namely, letter formation, size and proportion, spacing, slant, alignment, and line quality. Therefore, the researchers are positive that WriteRite can benefit dysgraphic children in improving their structured instruction on handwriting and how to form letters.

\section{ACKNOWLEDGEMENT}

The authors would like to thank the students who have participated in the experiments and teachers for their encouragement and cooperation in this study.

\section{REFERENCES}

Barisic, K., Kohnen, S., \& Nickels, L. (2017). Developmental graphemic buffer dysgraphia in English: A single case study. Cognitive Neuropsychology. 34(3-4), 94-118. doi.org/10.1080/02643294.2017.1359154

Berninger, V. W., Nagy, W., Tanimoto, S., Thompson, R., \& Abbott, R. D. (2015). Computer instruction in handwriting, spelling, and composing for students with specific learning disabilities in grades 4-9. Computers \& Education, 81, 154-168.

Bryant, B. R., Ok, M., Kang, E. Y., Kim, M. K., Lang, R., Bryant, D. P., \& Pfannestiel, K. (2015). Performance of fourth-grade students with learning disabilities on multiplication facts comparing teacher-mediated and technology mediated interventions: A preliminary investigation. Journal of Behavioral Education, 24(2), 255-272. doi:10.1007/s10864015-9218-z

Bryant, B. R., Seok, S., Ok, M. \& Bryant, D. P. (2012). Individuals with intellectual and/or developmental disabilities use of assistive technology devices in support provision. Journal of Special Education Technology, 27(2), 41-57.

Connell, T. O., Freed, G., \& Rothberg, M. (2010). Using Apple technology to support learning for students with sensory and learning disabilities. 
Cortiella C, Horowitz SH. (2014). The state of learning disabilities: Facts, trends, and emerging issues (3rd ed.). New York: National Center for Learning Disabilities. Retrieved from https://www.ncld.org/wp-content/ uploads/2014/11/2014-State-of-LD.pdf

Couse, L. J., \& Chen, D. W. (2010). A tablet computer for young children? Exploring its viability for early childhood education. Journal of Research on Technology in Education, 43(1), 75-96.

Giordano, D., \& Maiorana, F. (2014). Addressing dysgraphia with a mobile, web-based software with interactive feedback. IEEE-EMBS International Conference on Biomedical and Health Informatics (BHI), 264-268.

Graham, S., MaCarthur, C. A., \& Fitzgerald, J. (Eds.). (2007). Solving problems in the teaching of literacy. Best practices in writing instruction. New York, US: Guilford Press.

Halsband, U., \& Lange, R. K. (2006). Motor learning in man: A review of functional and clinical studies. Journal of Physiology-Paris, 99(4-6), 14-424. doi:10.1016/j.jphysparis.2006. 03.007

Kaikkonen, A., Kekäläinen, A., Cankar, M., Kallio T., \& Kankainen A. (2005). Usability testing of mobile application: A comparison between laboratory and field testing. Journal of Usability Studies, 1(1), 4-16.

Keller, M. (2001). Handwriting club: Using sensory integration strategies to improve handwriting. Intervention in School and Clinic, 37(1), 9-12.

Kushki, A., Schwellnus, H., Ilyas, F., \& Chau, T. (2011). Changes in kinetics and kinematics of handwriting during prolonged writing task in children with and without dysgraphia. Research in Developmental Disabilities, 32(3), 1058-64.

Mather, N., Wenddling, B., \& Roberts, R. (2009). Writing assessment and instruction for students with learning disabilities. San Francisco, CA: John Wiley \& Sons, Inc.

Mather, D.S. (2012). Ipsilateral printing in children's mirror-writing: A cause of specific learning disabilities? Canadian Journal of Experimental Psychology = Revue canadienne de psychologie experimentale, 66 (3), 172-80.

Miceli, G., \& Capasso, R. (2006). Spelling and dysgraphia. Cognitive Neuropsychology, 23(1), 110-134.

Niedo, J., Tanimoto, S., Thompson, R. H., Abbott, R. D., \& Berninger, V. W. (2016). Computerized instruction in translation strategies for students in upper elementary and middle school grades with persisting learning disabilities in written language. Learning Disabilities: A Multidisciplinary Journal, 21(2), 14-30. http://doi.org/10.18666/ LDMJ-2016-V21-I2-7751 
NAEYC (2012). Technology and interactive media as tools in early childhood programs serving children from birth through age 8. Washington, $D C$ : National Association for the Education of Young Children.

NCATE (2008). Professional standards for the accreditation of teacher preparation institutions. Washington, DC: National Council for Accreditation of Teacher Education.

O'Bannon, B., Puckett, K., \& Rakes, G. (2006). Computers in the schools using technology to support visual learning strategies. Computers in the schools, 125-137. doi:10.1300/J025v23n01_11

Palmis, S., Danna, J., Velay, J. L., \& Longcamp, M. (2017). Motor control of handwriting in the developing brain: A review. Cognitive Neuropsychology. 34(3-4), 187-204.

Peterson-Karlan, G. R., \& Parette, H. P. (2007). Technology-based tools to support writing by struggling writers. Assistive Technology Outcomes and Benefits, 7(1), 39-62.

Puranik C., \& Al Otaiba, S. (2012). Examining the contribution of handwriting and spelling to written expression in kindergarten children. Reading \& Writing, 25(7), 1523-1546.

Prunty, M., \& Barnett, A. L. (2017). Understanding handwriting difficulties: A comparison of children with and without motor impairment. Cognitive Neuropsychology, 34(3-4), 205-218. http://doi.org/10.1080/02643294. 2017.1376630

Raza, T. F., Arif, H., Darvagheh, S. H., \& Hajjdiab, H. (2017). Interactive mobile application for testing children with dysgraphia. Proceedings of the 9th International Conference on Machine Learning and Computing - ICMLC 2017, 432-436. doi.org/10.1145/3055635.3056599

Rello, L., \& Baeza-Yates, R. A. (2013). Good fonts for dyslexia. Proceedings of the 15th International ACM SIGACCESS Conference of Computers and Accessibility (ASSETS 2013), 1-8.

Steele, E. C., Weber, K. P., McLaughlin, T. F., Donica, D., Derby, K. M., \& McKenzie, M. (2015). Employing handwriting without tears to teach a 4-year-old preschool student to write his name with the appropriate size, shape, and form combined with an imitate/trace/copy/memory procedure. Journal of Educational Psychology, 8(4), 16-25.

Tanimoto, S., Thompson, R., Berninger, V., Nagy, W., \& Abbott, R. (2015). Computerized writing and reading instruction for students in grades 4 to 9 with specific learning disabilities affecting written language. Journal of Computer Assisted Learning, 31(6), 671-689.

Van Drempt, N., McCluskey, M., Lannin, N. (2011). A review of factors that influence adult handwriting performance. Australian Occupational Therapy Journal, 58(5), 321-328. 